\title{
Я-НЕИЗВЕСТНОЕ В ДОСТИЖЕНИИ САМОТОЖДЕСТВА И САМОПРЕОБРАЗОВАНИИ ЛИЧНОСТИ
}

\author{
Е.Б. СТАРОВОЙТЕНКО ${ }^{a}$, С.А. ЩЕБЕТЕНКО ${ }^{a, b}$
}

\begin{abstract}
${ }^{a}$ Национальньй исследовательский университет «Высшая школа экономики», 101000, Россия, Москва, ул. Мясниикал, д. 20

${ }^{b}$ Пермский государственный национальный исследовательский университет, 614990, г. Пермь, ул. Букирева, 15
\end{abstract}

\begin{abstract}
Резюме
В исследовании, представленном в данной статье, впервые предлагается разносторонняя разработка проблемы Я-Неизвестного. Она охватывает его генез, условия существования, его связи с Я-Известным и парадоксальность этих связей, субъектный характер его поиска и раскрытия, его влияние на процессы достижения самотождества Я и самопреобразования личности. Вводится авторское определение Я-Неизвестного как осознанного личностью незнания себя, преодолеваемого в рефлексии, отношениях с другими и продуктивном действии. Исследование проведено персонологическим методом, состоящим в построении и интеграции ряда моделей: теоретико-герменевтической, или культурной, Я-Неизвестного, эмпирических предпосылок изучения Я-Неизвестного, построения «Вопросника Неизвестного Я». Обоснована парадоксальность отношения Я-Неизвестного с Я-Известным. Под «парадоксом» понимается такое соотношение бинарных оппозиций, в котором каждая из них необходима для существования другой, равноценна другой, обладает свойствами, определяемыми связями с другой, может находиться в конструктивном согласовании с другой. Выделены аспекты Я-Неизвестного, не получившие ранее концептуального и эмпирического раскрытия. В частности, выраженность Я-Неизвестного в контексте отношений личности; ипостаси Я-Неизвестного; содержания Я-Неизвестного; Я-Неизвестное в измерении возможностей и потенциала личности; Я-Неизвестное в возрастной динамике индивидуальной жизни; Я-Неизвестное во взаимодействии со значимым Другим; Я-Неизвестное в расширенном интериндивидуальном пространстве; Я-Неизвестное в структуре Я-концепции; Я-Неизвестное как признак тождества и разотождествления Я с собой; мотивация поиска и раскрытия Я-Неизвестного; Я-Неизвестное как условие самопреобразования личности; культурные и индивидуальные источники «знания о незнании себя».
\end{abstract}

Ключевые слова: Я, Я-Неизвестное, самотождество Я, разотождествление с собой, парадоксы самотождества, самопреобразование, отношение, Другой, культура, герменевтика, модель.

Публикация подготовлена в ходе проведения исследования (проект № 20-01-010) в рамках Программы «Научный фонд Национального исследовательского университета "Высшая школа экономики” (НИУ ВШЭ)» в 2020-2021 гг. и в рамках государственной поддержки ведущих университетов Российской Федерации «5-100». 


\section{Введение}

Данная статья освещает исследование, направленное на обоснование роли категории и феномена «Я-Неизвестное» в психологическом изучении личности. Восполняя недостаток внимания отечественных исследователей к проблеме «неизвестности Я для себя», мы представляем модели Я-Неизвестного, выявляющие его генез, формы, условия существования и участие в процессах, конституирующих развитие Я. Разработана система эмпирических параметров для создания методики обнаружения и самооценки Я-Неизвестного.

На наш взгляд, постановка проблемы Я-Неизвестного означает обращение исследователей не столько к ставшему Я, которое дано личности в устойчивом субъективном образе или концепции, сколько к жизненному становлению Я, к достижению и поддержанию самотождества, а также к разотождествлению Я с собой и обновлению себя путем самопреобразования. Только в индивидуальном жизненном движении Я возможно субъективное открытие незнания себя, проблематизация себя-известного и преодоление неизвестности себя путем обнаружения и реализации новых аспектов Я.

Рассмотрение Я-Неизвестного в качестве предмета психологического познания отвечает устремлениям любой науки в мир незнаемого, за горизонты добытого знания, к раскрытию нового и к творчеству, изменяющему каноны культуры и научного мировоззрения. Общими эпистемологическими предпосылками обращения к Я-Неизвестному являются науки, в которых «неизвестность» выступает не только констатацией недостатка знания об изучаемой реальности и стимулом к ее исследованию, «неизвестное» становится особым фокусом мысли ученых, касающейся генеза незнаемого в изучаемом предмете, его соотношения со знанием, его ресурса для умножения знаемого, рефлексии его поиска и раскрытия учеными, а также его значения как «тайны» культуры, притягивающей человеческое самопознание, талант и гениальность.

Во-первых, такой наукой является учение о бытии, в котором основной целью человека определяется постижение «тайны бытия», путь к которой лишь увеличивает пространство незнания и умножает загадки процесса познания. «Горизонт знания открывается чем-то не вполне знаемым - разумом, его существованием... Незнаемое - существование, не сводимое к знанию, то есть бытие» (Мамардашвили, 1997, с. 328). Во-вторых, учение о познании, акцентирующее, наряду со способами и методами поиска знания о мире, способы и методы поиска «незнания», ведущего к изменению координат познавательной деятельности ученых в направлении расширения зон еще не реализованных возможностей и перспектив познания в мире и культуре. Втретьих, психология мышления, в которой подчеркивается роль мыслительной деятельности, предполагающей единство чувствительности человека к незнанию, интуиции своего незнания, приобретения знания о своем незнании, мысленного перехода от незнания к знанию и выражению его в дискурсивной форме. Универсальным приемом актуализации незнаемого определяется интеллектуальный поворот объектов различными сторонами друг к другу, 
вскрытие неизвестных отношений этих сторон и движение вглубь объектов, к их потаенной сущности. В-четвертых, психология рефлексии, обращающаяся к мысли Я о себе, о своей жизни, о своем познании и деятельности. Важным является смещение исследовательских акцентов данной науки на оппозиции знание Я - незнание Я, на интуитивно-мыслительный поиск личностью неизвестного Я, на формулировку проблемы снятия этой неизвестности, на добывание нового знания о себе на основе мысленного преодоления незнания. Кроме того, на отказ личности от полного прояснения неизвестного «себя» при нахождении парадоксального равновесия известности - неизвестности Я. В-пятых, психология Я, раскрывающая, что Я для личности не исчерпывается знанием о нем и означением его и что субъективная значимость и масштаб собственного Я определяются осознанием и принятием существования в нем своей «потаенной самости», своей «темноты для себя», «“слепого пятна” в самосознании», «неизъяснимой глубины собственного бытия», «неозначенного Я». Скрытое, данное в возможности Я, рассматривается как потенциал самопознания, прорывающегося за границы наличного Я-бытия. Тайна Я может высветить то, что мы можем знать о себе, и приобретенное знание становится шагом, приближающим к этой тайне. В этом - «продуктивная сторона нашего сознания» (Мамардашвили, 1997). В-шестых, психология метакогниций, которая характеризует сознательный контроль собственных когнитивных процессов, вовлеченных в научение (Flavell, 1979). Осознание и идентификация некоторых когнитивных и мотивационных состояний как «скрытых от индивида» может иметь существенное значение и для научения, и для прочих поведенческих паттернов.

Системно реализовать указанные эпистемологические предпосылки изучения Я-Неизвестного позволяет персонология (Петровский, 2013; Петровский, Старовойтенко, 2012; Старовойтенко, 2015; 2018; Исаева, 2013) как современное направление психологии личности, развивающееся в парадигмах «синтеза» мультидисциплинарных идей о личности и «интеграции» герменевтического (культурного), теоретического, эмпирического, феноменологического и практико-ориентированного подходов к познанию личности. В нашем исследовании методом синтеза идей из_текстов философско-психологической культуры разработана принципиально новая герменевтическая модель Я-Неизвестного, вскрывающая парадоксальность его отношения с ЯИзвестным. Под «парадоксом» понимается такое соотношение бинарных оппозиций, в котором каждая из них необходима для существования другой, равноценна другой, обладает свойствами, определяемыми связями с другой, может находиться в конструктивном согласовании с другой. В герменевтической модели обосновывается роль Я-Неизвестного в достижении осознанного самотождества, его ресурсность для самопреобразования на основе конструктивного разотождествления Я с собой. В коммуникации с указанной моделью построена модель, обобщающая результаты эмпирических исследований проблемы Я-Неизвестного. На основе синтеза моделей намечена структура методики, ориентированной на изучение и диагностику Я-Неизвестного личности. Речь идет о создании инструментария, позволяющего личности глубже осознать 
присутствие незнаемого в себе, принять его в качестве значимого аспекта Я, поставить его в соотношение с Я-Известным, проблематизировать самотождество и открыть новые возможности для саморазвития.

Основой разработки герменевтической модели послужили работы М.К. Мамардашвили и Ж. Лакана, ставшие классикой гуманитарной культуры. Среди авторов, сделавших вклады в современное знание о Я, указанные мыслители выделяются особым интересом и глубиной понимания проблемы Я-Неизвестного. Различия в парадигмах мышления и в дискурсах этих исследователей не являются препятствием к синтезу их идей и развитию на этой основе новых концепций Я в персонологическом контексте. Представляемая ниже герменевтическая модель является результатом авторской экспликации, дополнения и систематизации положений о Я-Неизвестном, выдвинутых данными авторами (Лакан, 2009; Мамардашвили, 1997).

\section{Герменевтическая модель Я-Неизвестного}

Модель включает определения основных категорий, формирующих персонологический подход к проблеме Я-Неизвестного, а также континуум идей, составляющих данный подход.

К категориям изучения Я-Неизвестного относятся:

«Личность» - единство способностей индивида переживать, познавать, воссоздавать и преобразовывать себя;

«Я-сам» или «собственное Я» - осознанная, означенная знаком Я единая самость личности, ядро ее субъектности;

«Я-живущее» - Я, вовлеченное в конкретные моменты проживания, объект для Я-сам, обладающий при этом собственной субъектностью;

«Удвоение Я-бытия» - существование Я в качестве Я-сам и Я-живущего;

«Самотождество» - переживание и знание о совпадении, идентичности, различии и относительной гармонии Я-сам и Я-живущего;

«Разотождествление с собой» - переживание и осознание несовпадения Я-сам с Я-живущим;

Самопреобразование - изменения Я самого себя путем достижения самотождества, разотождествления с собой и воссоединения с собой на более высоком уровне;

Я-Известное - Я, представленное в образе и концепции «себя» как обладающее характеристиками, раскрытыми в самопознании или посредством других людей;

Я-Неизвестное - осознанное личностью незнание себя в тех или иных аспектах, преодолеваемое в рефлексии, отношениях с другими и продуктивном действии;

«Парадокс Я-Неизвестного» - взаимная необходимость и равноценность Я-Неизвестного и Я-Известного в самопознании, в достижении самотождества Я и самопреобразовании.

Приведенные категории конституируют и получают раскрытие в следующих идеях о Я-Неизвестном. 


\section{Я-Неизвестное в отношениях личности}

Исследование Я-Неизвестного может основываться на определении личности в качестве Я как источника и субъекта жизненных отношений к значимостям. Личность или «полный человек» - это «тот, кто способен практиковать в жизни максимальное количество отношений как единиц человеческой души» (Мамардашвили, 1997, с. 317). Я-в-отношениях - это фактически Я-живущее. Отношения имеют ценностные ориентиры, развиваются как эстетическое или этическое, познавательное или религиозное, деятельное, творческое или рефлексивное (Старовойтенко, 2015). Каждая значимость, встреченная личностью в мире, в среде людей, или собственном Я, притягивает, воплощает и выражает определенную композицию ценностных отношений. Постоянство отношений и их сочетаний, которые осознанно присваиваются личностью «себе» и субъективно определяют ее внутреннюю устойчивость «для себя», выступает одним из оснований самотождества Я. Вместе с тем реализующиеся отношения непрерывно посылают вызовы самотождеству и выявляют неизвестность для Я-сам его новых сторон, появившихся в движении жизни. Диалог Я-сам личности с Яв-отношениях, «ныряние в жизнь и в себя» подвергает самотождество испытанию, вызывает разотождествление, расставание с собой, порождая неизвестные ранее феномены и качества Я. «Нырять в себя означает, прежде всего, избавляться... от своего Я, которое дано, то, которое приобретено, которое мы считаем самим собой или своей собственностью» (Мамардашвили, 1997, с. 441).

Собственное Я или Я-сам личности является, с одной стороны, реальным субъектом, обладающим телесно-душевными способностями воссоздавать жизнь, с другой стороны, субъектом, рефлексивно «сконструированным» посредством культурного знака Я, внутренне удерживающего и закрепляющего относительное единство реального субъекта. В связи с этим у «Я-сам» есть риски дереализации, преодолеваемые его свободным погружением в отношения и проживанием подлинных состояний, которые Я может затем присвоить, означить и идентифицировать с собой, сохраняя или обновляя самотождество. «У каждого из нас есть хотя и псевдоконструкция, но реально существующее в нас наше identity, наша “яйная" тождественность, а она, оказывается, загораживает реальность, и с помощью некоторых состояний, где нам дано время в чистом виде, мы можем срезать эту конструкцию, и тогда перед нами выступает то, что на самом деле...» (Там же, с. 356 ).

Я, вовлеченное в отношения, пребывающее одновременно в качестве субъекта и объекта текущей жизни, удваивающее свое бытие и вставшее в отношение к себе, оказывается способным разотождествиться с собой, встретиться с собой в своих незнакомых состояниях, поведенческих актах или свойствах и осознать их как Я-Неизвестное. «Только при отделении себя от самого себя, во-первых, открывается пространство реальности, континуум движения... И во-вторых, без этого отделения перед нами не выступили бы наши состояния... не реализовались бы отношения» (Там же, с. 116).

Я-Неизвестное, или «ненайденное Я», - это Я, еще не вошедшее ни в один из знаемых «потоков жизни», ни в одно из жизненных отношений, не ставшее 
смысловым фокусом отношения к себе, не влившееся в мир осознаваемых значимостей, не укрепившее самотождественность Я.

В каких взаимосвязях могут находиться Я-Неизвестное и самотождество Я?

1. Это может быть сбережение, «консервация» самотождества, достигнутого путем социальных идентификаций и удерживающего Я от вступления в персональные отношения, несущие риски разотождествления с собой и требующие нового взгляда на себя. Такое самотождество «развязать, расщепить чисто рациональными актами невозможно» (Там же, с. 46). «Незрячее Я» не допускает фактов, не приобретает опыта, не проживает состояний, которые могут разрушить драгоценное совпадение с самим собой. Отрицается возможность существования незнаемого Я, встречи с Я-Неизвестным. Если же оно проступает в сознание, то отбрасывается как субъективная иллюзия.

2. Это защита от Я-Неизвестного в отношениях для сохранения уверенности в своем бытии «только собой». Добываются подтверждения своего самотождества посредством мнений и оценок других людей; культивируются отношения, имеющие постоянные формы и не несущие новых переживаний и впечатлений. Не инициируются новые отношения, где Я-Неизвестное может стать возможностью для самоизменений.

3. Это регресс самотождества, обеднение Я-для-себя или за счет активного отчуждения Я-Неизвестного, проступающего в отношениях и оцениваемого личностью как «не мое», «чужое», «другое, чем Я», или за счет превращения части Я-Известного в «переставшее быть моим» и погружение ее в темноту, неизвестность забвения.

4. Вступление Я в максимум возможных отношений; активность жизни; вчувствование и рефлексивная связь с Я-живущим. Проживание новых состояний и совершение действий, связанных со значимостями; реализация отношения Я-сам - Я-живущий, в которых гармонично связаны разотождествление и отождествление с собой. Поиск Я-Неизвестного в обновляющихся отношениях, включая отношение к себе и к самому Я-Неизвестному. Определение Я-Неизвестного как значимого аспекта Я, раскрытие ЯНеизвестного и интеграция нового знания в Я как шаг в самопреобразовании: «Есть меняющие Я открытия себя» (Там же, с. 116).

5. Поддержание самотождества не только путем рефлексии, оперирующей знанием о Я, и посредством подтверждения знаемого Я со стороны других, но и на основе полагания «незнаемого Я» как важного аспекта «самого себя» и ценности, способствующей осознанному совпадению Я с собой и укрепляющей его верность себе. Например, «загадка собственного творчества» и встреча Я с ее выражением в мире вызывают сознание интегрированности и силы своего Я и предчувствие его новых возможностей.

\section{Проживание Я-Неизвестного в отношениях}

Для того чтобы встретиться с Я-Неизвестным, нужно сполна присутствовать в текущей жизни. Полнота присутствия способствует жизненному проявлению 
«подлинного Я», которое заключает в себе значительно больше неизвестного, чем известного. Проживать и встать в отношение к этому Я-Неизвестному значит обратиться к своему «высшему потенциалу», «предназначению», «вершинному смыслу жизни».

Присутствие «себя» и Я-Неизвестного в жизни и отношениях дается личности посредством различных психических и практических функщий. Оно конституируется самопереживаниями, самоощущениями, самовосприятием, предчувствиями себя, представлениями о себе, рефлексией как мыслью о себе, желаниями и действиями, направленными на себя. Можно чувствовать Я-Неизвестное; можно предвидеть появление Я-Неизвестного; можно понимать, что чего-то не знаешь о себе; можно догадываться о существовании ЯНеизвестного; можно интуитивно уловить во впечатлении или сновидении ЯНеизвестное; можно вообразить неизвестную себе область души; можно отрефлексировать Я-Неизвестное как важный аспект Я-сам.

Приведем примеры феноменов проживания Я-Неизвестного в отношениях (к себе, к другим), которые мы обнаружили благодаря произведениям Достоевского, Чехова, Тютчева, Пруста, Мамардашвили.

- Переживание и рефлексия необъяснимого присутствия высшего в себе, например, ощущения красоты. Сознание неизвестности происхождения этого чувства. Неизъяснимая грусть при виде прекрасного: «Я не знаю, почему красота женщины вызывает у меня такую печаль». Незнание, откуда приходит потрясение красотой, например, при впечатлении о «женщине, садящейся в машину...»; проживание «акта красоты», имеющего глубинный источник.

- Переживание невозможности пребывать далее в определенном месте или окружении и неизвестности своего «не могу»: «Чувствую, что не могу жить здесь.... и не знаю, откуда это мое чувство».

- Переживание и понимание, что во многом остается неизвестным собственное положение в мире, среди людей, в отношении к себе, что основная задача - «узнать свое действительное положение».

- Предчувствие неизвестной ранее радости жизни, возможности «быть поновому живым».

- Чувство присутствия себя-неизвестного в своих желаниях; незнание, откуда собственная задетость, затронутость, очарованность чем-либо; непонимание, почему становятся значимы «неизвестные вещи в моей жизни».

- Интуиция избыточности проживаемой и познаваемой ситуации; неизвестность для себя соотношения своих возможностей и невозможностей, пределов овладения ситуацией и зависимости от нее.

- Осознание неизвестности того, что я на самом деле «воспроизвожу и произвожу своей жизнью» («нам не дано предугадать, как наше слово отзовется...») и в чем смысл моего незнания для меня, других людей и их жизней.

- Рефлексия неизвестности генеза «себя» в своей жизни: не знаю, почему я так думаю, так чувствую, так поступаю, считаю то или иное добром или злом, именно в этом человеке «ищу себя» и т.д.

Я-Неизвестное, появляющееся в жизни, сознании и отношениях личности, приобретает содержания, которые раскрываются Я-сам автономно или 
посредством других людей. Это могут быть, к примеру, определенные качества Я (доверчивость, доминантность, завистливость, влюбчивость и т.д.), его мотивы (достижение, власть, любовь, разрушение и т.д.), чувства (восхищение, страх, восторг, печаль и т.д,), ощущения (запах, прикосновение, боль, удовольствие и т.д.), образы (сон, фантазия, мечта, воображение), мысли (о своем теле, внутреннем мире, отношениях, поступках и т.д.), Я-оппозиции (вера неверие, вовлеченность - равнодушие, любовь - эгоизм, поступок - недеяние и т.д.), смыслы (полнота жизни, исполнение предназначения, поиск истины, творчество и т.д.), действия (предметно-практические, информационные, ценностные, коммуникативные, познавательные и т.д.), представления других о Я (позитивные, обесценивающие, идеализирующие, негативные и т.д.).

Процессы проживания, феномены, содержания Я-Неизвестного могут стать объектами самопознания личности как равноценные Я-Известному, раскрываться в парадоксальном единстве с ним (знать себя означает умножать и понимать незнание себя), восполнять и подвергать сомнению самотождественность Я.

\section{Ипостаси Я-Неизвестного}

Я как субъект и объект для себя обладает множеством форм (Петровский, 2013; Старовойтенко, 2015), в которых рождается и проявляет себя ЯНеизвестное. Незнаемыми могут быть аспекты «абсолютного Я», «телесного Я», «глубинного Я», «феноменального Я», «означенного Я». Эти аспекты определяются как ипостаси Я-Неизвестного.

Неизвестное «телесное Я»: Я-сам может не знать потенциалы и ограничения своего тела, те или иные грани своей привлекательности, оценки другими своего облика, не улавливать возрастную динамику своей телесности, не открыть то, что все прошлое и настоящее нашей души, принадлежа нашему телу и имея в нем свой след, «находится в нашем владении».

Неизвестное «злубинное Я»: от Я-сам утаен изначальный субъект собственной жизни, ядро еще не реализованных возможностей, «тот, кто в темноте», «тот, кто может», «кого еще предстоит найти», «кто способен начать работу по преобразованию себя» (Мамардашвили, 1997, с. 61). Это дорефлексивное, потенциальное, упускаемое, сокровенное Я (Петровский, 2014).

Неизвестное «феноменальное Я»: Я-сам не знает многое о себе как проживающем жизнь, реагирующем на явления, переживающем состояния, соединенном с конкретными жизненными ситуациями. Я-живущий как «незнакомец» может ускользать от самосознания, будучи захваченным другими людьми, собственными желаниями и чувствами, властью обстоятельств.

Неизвестное «означенное Я»: в осознанных Я-сам содержаниях знака Я появляются зоны неопределенности и проблемности означения либо зоны неозначенности. Например, Я-знак не приобретает рефлексивной связи с новыми признаками самотождества (это - не Я, это - Другой, это - Не-Я), и они отчуждаются от самосознания и Я-сам, не участвуя в поддержании и дальнейшем «конструировании» самоидентичности. 
Неизвестное «абсолютное Я»: от Я-сам может быть скрыт внутренний доступ к истине, красоте, состраданию другим, вере, совести, внутренним истокам творчества - тому вечному, что постигается в соединении индивидуального с абсолютом. Для достижения абсолютного Я необходимо преодолеть границы рефлексивного Я, и в этом плане данную форму Я-неизвестного можно обозначить как «трансгрессивное Я» (Петровский, 2014).

Я и каждая его форма включает три временнь́х типа: Я-в-прошлом, Я-внастоящем и Я-в-будущем. Их взаимосвязь указывает на непрерывность существования Я во времени, преемственность его жизненной самореализации, на постоянство самотождества наряду с возможностями самоизменений.

Каждый момент активности Я-живущего, оставляя собственное Я самим собой или возвращая его к себе на новом уровне, сохраняет в Я-сам свой субъектный след. В этом самодвижении Я нет невозврата: Я может свободно или посредством рефлексивных усилий вызвать к жизни Я-в-прошлом - любое свое бывшее состояние, любой образ, любую предметную форму, которые помнятся или приобрели неизвестность в динамике внутренней жизни. ЯНеизвестное в этом процессе парадоксально усиливает интенцию к воссозданию «исчезнувшего» Я и проживанию самотождества. М. Пруст писал: «То я, которым я был тогда и которое так давно исчезло, снова было рядом со мной настолько, что я как будто слышал непосредственно предшествовавшие слова... Я снова был тем существом, которое стремилось укрыться в объятиях бабушки» (цит. по: Мамардашвили, 1997, с. 191).

Я-в-будущем представлено для Я как Я-возможное и Я-невозможное, состоящие в осознании того, что именно Я сможет или не сможет осуществить «по закону своего бытия» в дальнейшем течении жизни. В этих Я-могу и Яне-могу даны предположения личности о своих осознанных с опорой на прошлое и настоящее потенциалах и ограничениях, а также о наличии скрытых субъективных ресурсов и пределов в перспективе самоосуществления.

Личность не узнает и не поймет Я-в-настоящем, если является незнаемым для себя в прошлом или отчуждает себя в прошлое, не узнав себя в момент реального проживания, или если не открывает «смысла себя» на дальнюю перспективу. Без установления развивающей связи Я-Известного и ЯНеизвестного в трех временах своей жизни Я ограничено либо «застрявшим» и «застывшим» в определенном временно́м измерении самотождеством, либо диффузией «себя» в сплошном потоке времени, где проживание самотождества невозможно.

Временна́я непрерывность, транспектива $Я$ как признак развития самотождественности - это Я-прошлое, вложенное в Я-настоящее и продленное в Я-будущее. Самотождество и самопреобразование Я основываются на хорошей коммуникации этих временны́х типов Я, на нахождении, снятии или сбережении неизвестности себя в каждом временно́м измерении, а также на разотождествлении с собой в поиске и прояснении Я-Неизвестного и на установлении новых аутентичных соответствий между «опытом себя», «фактичностью себя» и «ожиданием себя». 
Добавляя к герменевтике ипостасей Я-Неизвестного некоторые данные наших предварительных эмпирических исследований, отметим следующее.

Я-неизвестное может выступать для Я-сам в ипостасях «доступного» и «недоступного» при оценке своих когнитивных способностей по преодолению незнания себя. Кроме того, присутствие Я-Неизвестного может переживаться и осознаваться как «важное» и «неважное» для Я. Примечательно, что эти ипостаси Я-Неизвестного отличаются от собственно чувства и осознания незнаемого, выражающегося в суждениях типа «Я не знаю, зачем я живу». Они актуализируются в отношении личности к Я-неизвестному.

Я-Неизвестное предположительно функционирует также в ипостасях устойчивой «черты» личности или альтернативной «ситуативной характеристики» сознания, отношений или поведения личности. В случае ЯНеизвестного как черты личность полагает, что представляет собой «резервуар множества тайн и загадок», где можно найти новые основания для своего самотождества. В случае ситуативно появившегося Я-Неизвестного, например в «потоковых состояниях», у личности может возникнуть нетипичное для нее временное впечатление о своей «непредсказуемости», «непрозрачности», что означает процесс разотождествления с собой.

\section{Отношение личности к Я-Неизвестному}

В процессе становления общего самоотношения может получить развитие отношение личности к Я-Неизвестному. Оно состоит в том, чтобы «встать над собственной рефлексией», признать свою «слепоту», пройти путь к себе, становясь «зрячим», «проснуться по отношению к самому себе», преодолеть «иллюзии себя», реализоваться в максимальной полноте и взрослеть, расширяя, обогащая свою самотождественность. Отношение к Я-Неизвестному может состоять в усиленном эмоциональном вживании в тайну Я, в искренней оценке важности Я-Неизвестного для себя и для других, в интеллектуальном поиске доступа к Я-Неизвестному, в рефлексивном творчестве, в использовании культурных средств обнаружения и раскрытия Я-незнаемого. Оно состоит также в достижении творческого озарения, что «Я - это больше, чем я знаю о себе», в открытии неизвестного «себя» при самоиспытании действием или поступком, в самовыражении и в сделанном Я-сам открытии, что обретенное Я стало еще одной гранью его самотождества и эффектом самопреобразования. Отношение к себе в аспекте Я-Неизвестного реализуется в развертке других жизненных отношений и непосредственно не определяется свойствами субъекта: свойства, по выражению М.К. Мамардашвили, не предшествуют приобретению опыта проживания. Устойчивый самотождественный субъект должен «выйти из себя», встретить дары и удары отношений, чтобы узнать себя.

Что значит встать в отношение к Я-Неизвестному?

- Установить мысленную связь Я-незнаемого с Я-знаемым, ввести осознанное незнание себя в контекст известного о себе как проблему самопознания; 
- познавать Я-Неизвестное в поисках ответа на коренные вопросы бытия: почему, например, я люблю, или могу ли ценить любимое мною в его свободном существовании;

- постигать Я-Неизвестное в аспекте «предела себя», например, в моментах высокого риска, жизненного прорыва, творчества, преодоления. «Самое красивое зрелище в человеке - когда человек идет на пределе того, на что вообще способен человек» (Мамардашвили, 1997, с. 66);

- принять, что есть Я-Неизвестное как «лучший другой Я»: «Я представил себе какую-то совершенно абстрактную, неясную, но переполняющую радость, ощущение другой жизни, другого Я, то есть другого самого себя» (Там же, с. 49);

- не избегать страдания по поводу того, что не найдено Я, которое может преобразовать трудную ситуацию или решить внутреннюю проблему, следовать этому переживанию в поисках Я-Неизвестного;

- переживать и ценить азарт и пафос в связи с поиском того Я-Неизвестного, которое полно активности и силы для совершенствования Я;

- расшифровывать Я-Неизвестное во впечатлениях: «Не всякое восприятие относится к категории впечатлений. И из того, что мы называем впечатлениями, мы что-то можем узнать о самих себе и о каких-то гармониях в действительном мире» (Там же, с. 133). Чтобы понять себя во впечатлении, нужен «опыт искусства», великий текст;

- восстанавливать историю действия, где проявилось Я-Неизвестное: понять генез Я-Неизвестного в действии, свои незнакомые реакции в ходе действия, моменты влияния неизвестности «себя» на действие, незнаемые последствия действия в мире, неизвестную отраженность Я-действующего в других людях;

- включиться в поиск Я-Неизвестного как в творчество, а также «внутри» творческой деятельности, например, создавать художественный или философский текст не потому, что мы что-то знаем или понимаем, а для того, чтобы испытать свое непонимание, свое незнание себя.

Отношение к Я-Неизвестному является, на наш взгляд, одним из главных условий достижения и развития самотождества. В этом отношении Я-Неизвестное становится субъективной значимостью; происходит осознанный поиск Я-Неизвестного; разотождествление с собой-известным превращается в ресурс самопреобразования; умножение незнания себя парадоксально служит расширению оснований самотождественности.

\section{Другой как источник возникновения и поиска Я-Неизвестного}

Я-Неизвестное как фокус самосознания субъекта в различных жизнеотношениях, а также предмет особого отношения личности часто обнаруживается во взаимодействии с другими людьми и в контексте отношения к конкретному Другому. Этот Другой присутствует во встречах личности с Я-Неизвестным, во-первых, в качестве человека, актуализирующего или «провоцирующего» во взаимодействии с ней появление ее незнаемого Я. Во-вторых, в качестве 
автора и носителя в своем внутреннем мире скрытого от личности представления о ней. В-третьих, в качестве «внутреннего Другого», в отношении к которому личность сталкивается с неизвестностью относительно части своих возможностей, желаний, мотивации поступков, смыслов, черт, границ поведения. В-четвертых, в качестве «значимости» для личности, неотъемлемого содержания мира ее Я, имманентного субъекта и объекта ее диалога с собой, в котором есть неизвестный потенциал ее саморазвития либо саморазрушения. В-пятых, в качестве части Мы, воспринимаемого миром и во многом непостижимого для личности.

Другой - это важнейшая и «сенсибилизированная», и «сенсибилизирующая» точка в мире Я личности: «если Я выхожу на точку, сенсибилизированную по отношению ко мне, то Я в этой точке воссоздаю себя или должен уметь воссоздать себя, то есть я отражаюсь в ней, а она отражается во мне... Эти взаимоотражения усложняют точки, находящиеся в этих отражениях...» (Мамардашвили, 1997, с. 444). В парадигме взаимных отражений или «измерений» отношения к Другому (Starovoytenko, 2018) Я-неизвестное приобретает многообразие форм, которые можно обозначить следующим образом:

Я-неизвестное-между-Я-и-Другим;

Я-неизвестное-в-Я-в-Другом;

Я-неизвестное-в-Другом-в-Я;

Я-неизвестное-в-Я-в-себе-с-Другим;

Я-неизвестное-в-Я-с-Другим-в-мире.

Направленный поиск и рефлексивное раскрытие Я-Неизвестного в измерениях отношения к Другому не исчерпывает всех способов обращения личности с незнанием «себя». Иногда, признав свое бессилие в самопознании или желая «запустить» спонтанные процессы открытий «себя», Я может осознанно оставить Я-Неизвестное в зоне непонимания и достигать самотождества, выдерживая неопределенность Я и находя в ней источники усиления «себя» и преобразования своих связей с Другим.

\section{Я-Неизвестное как культурный феномен}

Я-Неизвестное, выступая реальностью, объектом познания, понятием, символом и метафорой, многообразно представлено в культуре: художественной литературе, философии, психологии, изобразительном искусстве, имплицитных представлениях. Все области культуры могут взаимно преломлять знание о Я-Неизвестном, включая идеи о его культурной обусловленности. В частности, есть научно-психологические кейсы, где герменевтически акцентирован культурный генез Я-Неизвестного во взаимосвязях личности с другими людьми. Это, к примеру, герменевтика произведения Эдгара По «Украденное письмо», предложенная Ж. Лаканом (Лакан, 2009).

В кратком пересказе, релевантном анализу Ж. Лакана, текст «Украденного письма» повествует о следующем: 
Королева получает компрометирующее письмо, содержание которого нарушает королевский брачный договор. Письмо лежит на столе и может быть замечено Королем, который, однако, его не замечает. Но его видит Министр, определяет по взгляду Королевы его значимость и крадет его, подменяя на глазах у безгласной женщины другим, похожим. Королева в глубокой тревоге обращается в Полицию с требованием отыскать письмо, не называя Министра, но полицейские письма не находят и поручают дело частному Сыщику. Тот, предполагая, что письмо украдено Министром, разгадывает его ход, состоящий в «укрытии тайны путем ее помещения на самом видном месте», обнаруживает письмо и кладет на его место другое с ироническим текстом в адрес Министра. Тот видит подмену, но ничего сделать не может. Сыщик продает Полиции украденное письмо, дальнейшая судьба которого неизвестна...

Для Лакана украденное письмо является культурным символом «сокрытия Я в тексте» и воплощением «игры интерсубъективности», в которую вовлечены Королева и ее окружение. В отношениях к другим Королева выступает в триединстве «функциональных уровней построения человеческого Я» (Там же, с. 74). К этим уровням относятся: Я-символическое (причастность к королевскому брачному договору), Я-реальное (обладание письмом от неизвестного нам лица. соединение с ситуацией и фактом его кражи), Я-воображаемое (отраженность в других участниках ситуации кражи и поиска письма).

Текст письма в данном случае становится «культурным знаком» Я, которое испытывает ослабление всех своих функций, грозящее утратой самотождества. А именно, Я-символическое Королевы теряет признак верности брачному договору с Королем, Я-реальное охвачено тревогой и безмолвием, лишившись письма, Я-воображаемое ускользает в непроницаемость сознания и поведения Других (Министра, Сыщика, Полиции), скрывающих судьбу письма, а следовательно, будущее Королевы.

Вводя сюда категорию Я-Неизвестное, можно обнаружить его новые свойства. Это «запечатленность» в вещах, созданных культурой (наше Я странствует в мире неизвестными нам маршрутами, реализовавшись в наших текстах или отразившись в текстах других людей); это соотнесенность с социокультурными регламентами, канонами, договорами (наше Я оказывается одним из действующих лиц в системе заданных социальных связей и ролей в определенной культуре, подлинное положение которого ему самому во многом неизвестно); это необходимость означенности средствами языка собственного отражения в Других (Я останется не узнанным собою в мире других, не имея возможности речевой самоартикуляции и получения ответов на нее).

Я неизбежно встретится с ограничениями в поиске и раскрытии ЯНеизвестного, если не обратится к культурному контексту своей жизни и культурным инструментам самопознания и самовыражения. Так, Я-Неизвестное Королевы не стало бы «потерей себя в Других», если бы она сообщила Королю о своем желании соблюдать брачный договор с ним, несмотря на содержание письма, и вернула себе осознание самотождества «по закону королевской власти», конституированному культурой. «Уважение к договору, 
соединяющему мужчину и женщину, имеет для всего общества величайшую ценность, и ценность эта с незапамятных времен находила верховное свое воплощение в лицах королевской четы. Чета эта является символом важнейшего договора, согласующего мужскую природу с природой женской, и традиционно играет посредническую роль между всем тем, чего мы не знаем, с одной стороны, и общественным устройством, с другой» (Там же, с. 279).

В дополнение к культурным референциям Я-Неизвестного отметим, что внимание к его существованию может варьироваться в различных культурах. Отсюда важность его кросс-культурных исследований, а также перспективы обогащения герменевтических идей о Я-Неизвестном результатами таких исследований. Акцентируя западную традицию его осознания и поиска, нужно учитывать, что восточные культуры допускают бо́льшую степень неопределенности в существовании человека, чем западные культуры (Markus, Kitayama, 1991). Это может распространяться на представления человека о себе (DeMarree, Bobrowski, 2017) и на его впечатление о своей неизвестности для себя.

Таким образом, можно ожидать особую выраженность Я-Неизвестного у человека в восточных культурах. Я-Неизвестное в условиях данных культур может указывать на подвижность, релятивность индивидуального Я, связанную с легкостью разотождествлений Я с собой и большой изменчивостью Я-образа.

В нашем исследовании, выполняемом в персонологическом формате, важны взаимодополнение и синтез знаний о Я-Неизвестном, относящихся к разным областям познания личности и получаемых разными методами. Речь идет о теоретико-психологических идеях, найденных культурно-герменевтическим путем, и о результатах эмпирических исследований, имеющих референции к Я-Неизвестному и определенных нами как «эмпирические предпосылки» его изучения. Результаты герменевтики и эмпирических исследований представлены в едином формате, позволяющем разработать систему параметров Я-Неизвестного для построения новой методики его изучения.

\section{Модель эмпирических предпосылок изучения Я-Неизвестного}

Как известно, Я присуще переживание своей континуальности (Dunlop, 2017; McAdams, 1995), убежденность в том, что оно остается самим собой в разные моменты времени и в разных ситуациях. Я обладает также представлением о том, что каждая личность знает себя, обладает информацией о себе (Щебетенко, 2017), может делать выводы и прогнозы относительно своего поведения и своих внутренних состояний. По всей видимости, степень выраженности этого «знания себя» и «знания о своем знании» варьируется между разными людьми и внутрииндивидно в зависимости от ситуаций. Соответственно в определенных условиях для любой личности или для определенных людей больше, чем для других, может наблюдаться и выраженность незнания себя, т.е. Я-Неизвестного. Получение эмпирических фактов и создание рабочих моделей является важным шагом на пути изучения Я-Неизвестного. 


\section{Я-Неизвестное в соотношении с Я-конщепцией}

Наш анализ психологической литературы показал, что Я-Неизвестное как аспект Я-концепции до сих пор практически не оказывался в фокусе эмпирического анализа. Справедливо, однако, то, что в русле изучения Я-концепции разрабатывается большое количество других конструктов, обладающих разной степенью родства с Я-Неизвестным. Примерами могут быть Ясность Яконцепции (self-concept clarity - Campbell, 1990; Lodi-Smith, DeMarree, 2017), «неизвестное» (unknown) и «слепое пятно» (blind spot) в межличностном «окне Джохари» (Vazire, 2010) и «скрытое Я» (hidden self) в контексте психодинамической клинической практики (Schimmenti, 2012).

Я-Неизвестное можно трактовать как элемент Я-концепции, фиксирующий осознание/впечатление/переживание человеком своего незнания какихлибо качеств и характеристик собственный личности и своего поведения: «Знаю, что нечто о себе не знаю». В этом смысле Я-Неизвестное следует отличать от объективной ограниченности знания индивида о себе. Достаточно много работ, выполненных в самых разных сферах, посвящено несоответствию самооценки способностей, с одной стороны, и объективных показателей этих способностей - с другой (см. метасинтез исследований: Zell, Krizan, 2014). Такое расхождение между представлением о себе и фактом следует отличать от Я-Неизвестного. Последнее не является фактической оценкой знания или незнания индивидом данного качества своей личности и поведения. Напротив, это общее «впечатление $Я$ » о своей ограниченности в знании о себе и в понимании себя. Поэтому, например, осознание значительности ЯНеизвестного принципиально возможно при объективно глубоком и разностороннем знании человека о себе. Соответственно, возможно и отрицание человеком Я-Неизвестного при наличии впечатления энциклопедического знания себя в соотношении с объективно мизерной или неадекватной информацией о своей личности.

Я-Неизвестное нельзя считать прямым антиподом «знания о себе» (selfknowledge). Знание о себе трактуется как «информация о себе, доступная сознанию или рабочей памяти, которая может быть выражена символически» (Markus, 1983, p. 545). Такое знание о себе может накапливаться в разных сфеpax, что позволяет идентифицировать его несколько видов (Neisser, 1988). Противоположностью знания о себе, очевидно, является «незнание себя», выражающееся в отсутствии соответствующей информации. Используя схожую терминологию, Я-Неизвестное, напротив, можно определять как «информацию о незнании себя». Поэтому Я-Неизвестное можно считать особым случаем знания о себе. Так, например, человек может иметь мало знания о себе, в том числе - знания о Я-Неизвестном.

Я-Неизвестное очевидно (негативно) связано с Ясностью Я-конщепиии (self-concept clarity; Campbell, 1990; Lodi-Smith, DeMarree, 2017), которая, в свою очередь, может указывать на прочность самотождества Я. «Ясность» определяется как «степень, в которой содержимое Я-концепции (например, воспринимаемые личные свойства) определяется четко и уверенно, а также 
насколько оно внутренне согласовано и стабильно во времени» (Campbell et al., 1996, p. 141). Ясность Я-концепции сближается с психометрической трактовкой надежности; в этом смысле Я-концепция определяется как, возможно, психометрический конструкт, который у отдельных индивидов характеризуется одномерной надежностью и «внутренней согласованностью», в то время как у других он «распадается» и «раскалывается». Действительно, пункты Шкалы Ясности Я-концепции, обладавшие в оригинальном исследовании Кэмпбелл наибольшим факторным весом, такие: «Кажется, что мое мнение о себе часто меняется», «Мои представления о себе часто конфликтуют между собой» и т.п. В аспекте динамики «самотождества Я» данные утверждения личности могут указывать на его проблемный характер, на случаи разотождествления Я с собой и на догадки личности о наличии нового ЯНеизвестного.

(Не-)ясность Я-концепции, скорее всего, характеризуется перманентно меняющимися, внутренне противоречивыми представлениями человека о себе. Я-Неизвестное, напротив, предполагает внутренне согласованное, длящееся представление о неизвестности Я в себе и для себя. При этом противоположный полюс Я-Неизвестного характеризуется не внутренней и временной согласованностью представлений о незнании себя (т.е. Ясностью Я-концепции), а убежденностью индивида в том, что «он себя знает».

Предположительно Я-Неизвестное и Ясность Я-концепции связаны с саморегуляцией. Она может отрицательно коррелировать с Ясностью Я (Dunlop, 2017). Предположительно это обусловлено тем, что «высокорегулятивный» человек обладает разнообразным поведенческим репертуаром. Как следствие, высокая саморегуляция способствует сравнительно невысокой Ясности, поскольку такой человек допускает изменчивость своего поведения и личности. Саморегуляция также гипотетически отрицательно коррелирует с Я-Неизвестным: «высокорегулятивный» человек, скорее всего, обладает представлением об «известности» своей личности и поведения, что позволяет эффективно управлять собой. Выраженную саморегуляцию можно ожидать среди индивидов с пониженной Ясностью Я-концепции и повышенным $Я$ Известным'.

\section{Межличностный генез Я-Неизвестного}

Хотя Я-Неизвестное по своему происхождению должно быть связано с межличностным восприятием, было бы слишком прямолинейно считать его «простым продуктом». Так, Я-Неизвестное отлично от «слепого пятна» в

\footnotetext{
${ }^{1}$ Нельзя, однако, исключать того, что связь саморегуляции с Я-Неизвестным опосредована нейротизмом как чертой личности. В частности, возможно, что описываемая связь проявляется только при высоком нейротизме. Напротив, при низком нейротизме она становится нулевой или даже противоположной по своему знаку: эмоционально стабильные индивиды могут переживать «неизвестность себя» на фоне повышенной саморегуляции. Аналогичный паттерн можно ожидать для триады самооценка нейротизм Я-Неизвестное.
} 
модели так называемого окна Джохари (Gallrein et al., 2016; Luft, Ingham, 1955; Vazire, 2010). «Слепое пятно» представляет собой информацию о поведении индивида, доступную окружающим, но недоступную ему самому.

Отношения «слепого пятна» к Я-Неизвестному могут носить скорее функциональный характер. Так, внезапное обнаружение индивидом подобного «слепого пятна» в своей личности может способствовать «разрастанию» ЯНеизвестного. Таким образом, расширение знания о себе (например, в результате объективного/«психологического» тестирования - Youyou et al., 2015; Zell, Krizan, 2014) может парадоксально усиливать Я-Неизвестное. Рост знания и незнания Я о себе, имеющий межличностный источник, создает новые условия для достижения и поддержания самотождества и для постановки вопроса о самопреобразовании.

Я-Неизвестное следует отличать от метаперцептивных суждений человека о себе, в частности от так называемого метаинсайma (meta-insight). Последний характеризует представления человека о том, что другие «иначе» видят его со стороны, т.е. в чем заключены их «своя правда» (известная ему) и их «заблуждения» об этом человеке (Carlson et al., 2011). В отличие от метаинсайта, Я-Неизвестное не предполагает четкого «знания о якобы скрытом». Напротив, это скорее общее допущение и ощущение человеком того, что «своя правда обо мне» у других людей может быть и «она мне неизвестна». Поэтому Я-Неизвестное может также находиться в неких функциональных отношениях с метаинсайтом. Так, например, человек с выраженным Я-Неизвестным может считать, что «взгляд на себя со стороны» для него закрыт, как и многие другие характеристики его личности. При этом отказ от поиска и раскрытия своего Я-Неизвестного «в других» может свидетельствовать о тенденции личности к потере возможностей развития самотождества в межиндивидуальном пространстве.

\section{Личностные детерминанть Я-Неизвестного}

Выраженность Я-Неизвестного может быть обусловлена различными качествами личности. Так, на изменчивость Я-Неизвестного может влиять степень рефлексивности (Леонтьев, Осин, 2014). Специфика этой связи, однако, требует своего изучения. Так, отношения рефлексивности с Я-Неизвестным могут носить U-образный характер. В частности, среди высокорефлексивных индивидов можно ожидать возникновения, так сказать, «эффекта Сократа»: частая и детальная рефлексия может порождать представления Я об «обширном неизвестном» («Я знаю, что ничего не знаю»). В то же время низкорефлексивные индивиды могут обоснованно полагать, что они, в свою очередь, также «знают, что ничего не знают» о себе. Однако до получения эмпирических фактов нельзя исключать и обратного эффекта: люди с ограничениями в рефлексивности могут производить и обратный «эффект анти-Сократа»: «Я знаю, что знаю о себе предостаточно». Есть все основания ожидать подобных ответов и при высокой рефлексивности. Будущие исследования должны дать более четкую картину природы этих 
отношений, ключ к которой может находиться среди переменных-модераторов, например, самооценки. Схожие связи можно ожидать между Я-Неизвестным и иными, родственными рефлексивности конструктами - потребностью в познании (Саcioppo, Petty, 1982), чертами нейротизма и открытости опыту (McCrae, John, 1992) и т.п. Эмпирические данные о личностной детерминации самопознания, а также осознания «Я-Неизвестного» могут иметь прогностическое значение для оценки перспектив развития и регресса самотождества Я у людей с различными качествами.

Приведенные герменевтическая и эмпирическая модели Я-Неизвестного составляют предпосылки для построения инструментария его дальнейшего исследования и диагностирования. Эти предпосылки мы преломляем и обобщаем в системе параметров изучения «Я-Неизвестного», часть которых находит отражение в разрабатываемой нами в настоящее время методике «Вопросник Я-Неизвестного».

\section{Параметры изучения Я-Неизвестного}

• Выраженность Я-Неизвестного в контексте отношения к Другому и отношения к себе;

- Я-Неизвестное в соотношении с Я-Известным;

- ипостаси Я-Неизвестного;

- содержания Я-Неизвестного;

- Я-Неизвестное в измерении возможностей и потенциала личности;

- рефлексия Я-Неизвестного;

- Я-Неизвестное в динамике индивидуальной жизни;

- Я-Неизвестное во взаимодействии Я со значимым Другим;

-Я-Неизвестное в расширенном интериндивидуальном пространстве;

-Я-Неизвестное в структуре Я-концепции;

- отношение личности к Я-Неизвестному: мотивация, оценка возможностей, рефлексия обнаружения Я-Неизвестного;

-детерминация Я-Неизвестного чертами и качествами личности;

- Я-Неизвестное как признак самотождества и разотождествления Я с собой;

• культурные и индивидуальные источники знания о Я-Неизвестном.

Инструментарий эмпирических исследований и диагностики Я-Неизвестного необходим в области раскрытия «незнания себя» как обширной психологической проблемы, а также в областях изучения самотождества Я и отношения личности к себе, включая активность в самопреобразовании.

Наряду с очевидным значением фундаментальных исследований Я-Неизвестного следует подчеркнуть роль использования концепции «Я-Неизвестного» в различных прикладных сферах. Так, Я-Неизвестное, осознанное личностью в качестве раскрываемого потенциала собственной активности, может быть обосновано как важное условие психического здоровья, а также стабильности, силы, целостности Я. Можно предположить, что рефлексивный 
поиск Я-Неизвестного и творческое обращение с ним являются существенными факторами успешности психотерапии, самопознания и саморазвития личности.

\section{Литература}

Исаева, А. Н. (2013). Знаемое и незнаемое «Я» в значимой жизненной ситуации. Мир психологии. Научно-методический журнал, 2, 85-96.

Лакан, Ж. (2009). «Я» в теории Фрейда и технике психоанализа. М.: Гнозис.

Леонтьев, Д. А., Осин, Е. Н. (2014). Рефлексия «хорошая» и «дурная»: от объяснительной модели к дифференциальной диагностике. Психология. Журнал Высшей школь экономики, 11(4), 110-135.

Мамардашвили, М. К. (1997). Психологическая топология пути. (М. Пруст «В поисках утраченного времени). СПб.: Русский Христианский гуманитарный институт.

Петровский, В. А. (2013). «Я» в персонологической перспективе. М.: Издательский дом НИУ ВШЭ.

Петровский, В. А. (2014). Я: конфигурации артефакта. Культурно-историческая психология, 10(1), 63-78.

Петровский, В. А., Старовойтенко, Е. Б. (2012). Наука личности: четыре проекта общей персонологии. Психология. Журнал Высшей школы экономики, 9(1), 21-39.

Старовойтенко, Е. Б. (2015). Персонология: жизнь личности в культуре. М.: Академический проект.

Старовойтенко, Е. Б. (2018). Я-неизвестное в отношениях личности к себе и Другому. Мир психологии. Научно-методический журнал, 3, 35-49.

Щебетенко, С. А. (2017). Черты личности в рефлексии и жизненных проявлениях человека (Докторская диссертация). Национальный исследовательский университет «Высшая школа экономики», Москва.

Ссылки на зарубежные источники см. в разделе References после англоязычного блока.

Старовойтенко Елена Борисовна - руководитель Центра фундаментальной и консультативной персонологии, департамент психологии, факультет социальных наук, Национальный исследовательский университет «Высшая школа экономики», доктор психологических наук, профессор.

Сфера научных интересов: методология психологии, теоретическая психология личности, персонология, психология жизненных отношений личности, культурная психология личности, психология познания, психология рефлексии.

Контакты: heletstaOS@yandex.ru

Щебетенко Сергей Александрович - профессор, департамент психологии, Национальный исследовательский университет «Высшая школа экономики»; профессор, кафедра психологии развития, Пермский государственный национальный исследовательский университет, доктор психологических наук.

Сфера научных интересов: психология личности и индивидуальных различий, социальная психология, методология исследований.

Контакты: sshchebetenko@hse.ru 


\title{
Unknown Self in Reaching Self-Identity and Self-Transformation
}

\author{
E.B. Starovoytenko ${ }^{a}$, S.A. Shchebetenko ${ }^{a, b}$ \\ ${ }^{a}$ National Research University Higher School of Economics, 20 Myasnitskaya Str., Moscow, 101000, \\ Russian Federation \\ ${ }^{b}$ Perm State National Research University, 15, Bukireva Str., Perm, 614990, Russian Federation
}

\begin{abstract}
This paper provides a comprehensive view on a concept of the unknown self (UKS). The manuscript covers the origin of UKS, conditions of its existence, its associations with the known self (considering paradoxicality of these associations), subjectivity of its pursuit and disclosure, its impact on reaching self-identity and self-transformation. An original starting definition of UKS is introduced; UKS is defined as one's awareness of not knowing themselves. UKS is presumably overcome via reflection, relationships with others and productive actions. The study employed personological methods integrating thereby the theoretical hermeneutic (cultural) model of UKS, empirical backgrounds to studying UKS, a new "Unknown Self Scale". The authors justify a paradox of the relationships between UKS and the Known-Self. The paradox is treated as a particular balance of binary oppositions, wherein each opposition is necessary for its counterpart to exist, both are equivalent to each other, have properties determined by their mutual associations, be mutually consistent in a constructive manner. Several aspects of UKS, given previously insufficient attention paid, were highlighted in the paper including UKS and interpersonal relationships, hypostases of UKS, its content, UKS under one's opportunities and potentials, age changes in UKS, UKS and significant others, UKS within extended interpersonal space, UKS in the structure of self-concept, UKS as an attribute of self-identity and self-disidentification, motivation to search for and uncovering UKS, cultural and individual sources of "knowing about not knowing themselves".
\end{abstract}

Keywords: self, unknown self, self-identity, disidentification with self, paradoxes of self-identity, self-transformation, relation, other, culture, hermeneutics, model.

\section{References}

Cacioppo, J. T., \& Petty, R. E. (1982). The need for cognition. Journal of Personality and Social Psychology, 42, 116-131. doi:10.1037/0022-3514.42.1.116

Campbell, J. D. (1990). Self-esteem and clarity of the self-concept. Journal of Personality and Social Psychology, 59, 538-549. doi:10.1037/0022-3514.59.3.538

Campbell, J. D., Trapnell, P. D., Heine, S. J., Katz, I. M., Lavallee, L. F., \& Lehman, D. R. (1996). Selfconcept clarity: Measurement, personality correlates, and cultural boundaries. Journal of Personality and Social Psychology, 70, 141-156. doi:10.1037/0022-3514.70.1.141

Carlson, E. N., Vazire, S., \& Furr, R. M. (2011). Meta-insight: Do people really know how others see them? Journal of Personality and Social Psychology, 101, 831-846. doi:10.1037/a0024297

DeMarree, K. G., \& Bobrowski, M. E. (2017). Structure and validity of self-concept clarity measures. In J. Lodi-Smith \& K. G. DeMarree (Eds.), Self-concept clarity: Perspectives on assessment, 
research, and applications (pp. 1-17). Springer International Publishing. doi:10.1007/978-3-31971547-6_1

Dunlop, W. L. (2017). Situating self-concept clarity in the landscape of personality. In J. Lodi-Smith \& K. G. DeMarree (Eds.), Self-concept clarity: Perspectives on assessment, research, and applications (pp. 19-41). Springer International Publishing. doi:10.1007/978-3-319-71547-6_2

Flavell, J. H. (1979). Metacognition and cognitive monitoring: A new area of cognitive-developmental inquiry. American Psychologist, 34, 906-911. doi:10.1037/0003-066X.34.10.906

Gallrein, A.-M. B., Weßels, N. M., Carlson, E. N., \& Leising, D. (2016). I still cannot see it - A replication of blind spots in self-perception. Journal of Research in Personality, 60, 1-7. doi:10.1016/j.jrp.2015.10.002

Isaeva, A. N. (2013). Known and unknown self in a significant life situation. Mir Psikhologii. Nauchnometodicheskii Zhurnal, 2, 85-96. (in Russian)

Lacan, J. (2009). "Ya" v teorii Freida i tekhnike psikhoanaliza [Me in Freud's theory and in psychoanalytic technique]. Moscow: Gnozis. (in Russian; transl. of: Lacan, J. (1977). Le séminaire. Livre II. Le moi dans la théorie de Freud et dans la technique de la psychanalyse [Seminar. Vol. 2. Me in Freud's theory and in psychoanalytic technique]. Paris: Seuil. (in French))

Leontiev, D. A., \& Osin, E. N. (2014). "Good" and "bad" reflection: From an explanatory model to differential assessment. Psychology. Journal of Higher School of Economics, 11(4), 110-135. (in Russian)

Lodi-Smith, J., \& DeMarree, K. G. (Eds.). (2017). Self-concept clarity: Perspectives on assessment, research, and applications. Springer International Publishing. doi:10.1007/978-3-319-71547-6

Luft, J., \& Ingham, H. (1955). The Johari window, a graphic model of interpersonal awareness. In Proceedings of the Western Training Laboratory in Group Development. Los Angeles, CA: University of California, Los Angeles.

Mamardashvili, M. K. (1997). Psikhologicheskaya topologiya puti. (M. Proust "V poiskakh utrachennogo vremeni") [Psychological topology of the path (M. Proust "In Search of Lost Time")]. Saint Petersburg: Russkii Khristianskii gumanitarnyi institut. (in Russian)

Markus, H. (1983). Self-knowledge: An expanded view. Journal of Personality, 51, 543-565. doi:10.1111/j.1467-6494.1983.tb00344.x

Markus, H. R., \& Kitayama, S. (1991). Culture and the self: Implications for cognition, emotion, and motivation. Psychological Review, 98, 224-253. doi:10.1037/0033-295X.98.2.224

McAdams, D. P. (1995). What do we know when we know a person? Journal of Personality, 63, 365396. doi:10.1111/j.1467-6494.1995.tb00500.x

McCrae, R. R., \& John, O. P. (1992). An introduction to the five-factor model and its applications. Journal of Personality, 60, 175-215. doi:10.1111/j.1467-6494.1992.tb00970.x

Neisser, U. (1988). Five kinds of self knowledge. Philosophical Psychology, 1, 35-59. doi:10.1080/09515088808572924

Petrovsky, V. A. (2013). "Ya" v personologicheskoi perspective ["Me" in personological perspective]. Moscow: HSE Publishing House.

Petrovsky, V. A. (2014). Self: the configuration of artifact. Cultural-Historical Psychology, 10(1), 6378. (in Russian)

Petrovsky, V. A., \& Starovoitenko, E. B. (2012). The science of personality: Four projects of general personology. Psychology. Journal of Higher School of Economics, 9(1), 21-39. (in Russian)

Schimmenti, A. (2012). Unveiling the hidden self: Developmental trauma and pathological shame. Psychodynamic Practice, 18, 195-211. doi:10.1080/14753634.2012.664873 
Shchebetenko, S. A. (2017). Cherty lichnosti v refleksii $i$ zhiznennykh proyavleniyakh cheloveka [Personality traits in reflection and in life-manifestations of a person] (DSc dissertation). National Research University Higher School of Economics, Moscow, Russian Federation. (in Russian)

Starovoitenko, E. B. (2015). Personologiya: zhizn' lichnosti v kul'ture [Personology: Life of personality in culture]. Moscow: Akademicheskii proekt. (in Russian)

Starovoitenko, E. B. (2018). Ya-neizvestnoe v otnosheniyakh lichnosti k sebe i Drugomu [The unknown self in relations of personality to themselves and the Other]. Mir Psikhologii. Nauchnometodicheskii Zhurnal, 3, 35-49. (in Russian)

Starovoytenko, E. B. (2018). A non-dialogic relation to the other: Regression or opposition to dialogicity. Psychology. Journal of the Higher School of Economics, 15(4), 728-746.

Vazire, S. (2010). Who knows what about a person? The self-other knowledge asymmetry (SOKA) model.Journal of Personality and Social Psychology, 98, 281-300. doi:10.1037/a0017908

Youyou, W., Kosinski, M., \& Stillwell, D. (2015). Computer-based personality judgments are more accurate than those made by humans. Proceedings of the National Academy of Sciences, 112, 10361040. doi:10.1073/pnas.1418680112

Zell, E., \& Krizan, Z. (2014). Do people have insight into their abilities? A metasynthesis. Perspectives on Psychological Science, 9, 111-125. doi:10.1177/1745691613518075

Elena B. Starovoytenko - Professor, Head of the Centre for Fundamental and Consulting Personology, School of Psychology, Faculty of Social Sciences, National Research University Higher School of Economics, D.Sc.

Research Area: methodology of psychology, theoretical psychology of personality, personology, psychology of life relationships of personality, cultural personality psychology, psychology of cognition, psychology of reflection.

E-mail: helestaOS@yandex.ru

Sergei A. Shchebetenko - Professor, School of Psychology, National Research University Higher School of Economics; professor, department of developmental psychology, Perm State University, D.Sc.

Research Area: personality and individual differences, social psychology, methodology.

Email: sshchebetenko@hse.ru 